The INL is a

U.S. Department of Energy

National Laboratory

operated by

Battelle Energy Alliance

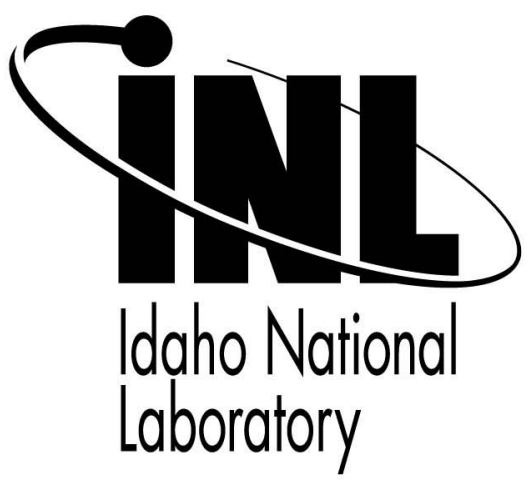

\section{Modeling and Simulation Approaches to Developing Human Performance Measures in Nuclear Industry}

\author{
Joint Meeting and Conference of the \\ Institute of Electrical and Electronics \\ Engineers (IEEE) and Human Performance I \\ Root Cause / Trending / Operating \\ Experience / and Self Assessment (HPRCT)
}

\author{
Bruce P. Hallbert \\ Jeffrey C. Joe \\ Molly J. Keefe \\ Julius J. Persensky
}

August 2007

This is a preprint of a paper intended for publication in a journal or proceedings. Since changes may be made before publication, this preprint should not be cited or reproduced without permission of the author. This document was prepared as an account of work sponsored by an agency of the United States Government. Neither the United States Government nor any agency thereof, or any of their employees, makes any warranty, expressed or implied, or assumes any legal liability or responsibility for any third party's use, or the results of such use, of any information, apparatus, product or process disclosed in this report, or represents that its use by such third party would not infringe privately owned rights. The views expressed in this paper are not necessarily those of the United States Government or the sponsoring agency. 


\title{
Modeling and Simulation Approaches to Developing Human Performance Measures in Nuclear Industry
}

\author{
Bruce P. Hallbert ${ }^{1}$, Jeffrey C. Joe ${ }^{1}$, Molly J. Keefe ${ }^{2}$, and Julius J. Persensky ${ }^{2}$ \\ ${ }^{1}$ Human Factors, Instrumentation, and Control Systems Department, Idaho National Laboratory, Idaho Falls, USA \\ \{Bruce.Hallbert, Jeffrey.Joe\}@inl.gov \\ ${ }^{2}$ Office of Nuclear Regulatory Research, U.S. Nuclear Regulatory Commission, Washington DC, USA \\ $\{$ mjk2,jjp2\}@inl.gov
}

\begin{abstract}
Human performance is a key component to the safe operation of nuclear power plants. Further, human performance is quite variable, and while some variability may be random, much of it may be attributed to factors that are difficult to assess. There is a need to identify and assess aspects of human performance that relate to plant safety and to develop measures that can be used to successfully assess human performance for purposes of research that can lead to technical basis for developing human factors review criteria.
\end{abstract}

\section{INTRODUCTION}

U.S. Nuclear Regulatory Commission (NRC) sponsored research [1] and various nuclear industry groups and associations [2] have recognized that human performance is a key component in the safe operation of nuclear power plants, and the NRC has designated it as a crosscutting element of the Reactor Oversight Process (ROP). Variability in human performance occurs from day to day, across activities, which vary in complexity, workgroups, and across plants, contributing to the uncertainty in the outcomes of plant performance. Some of this variability may be random, though much of the variability may be attributed to factors that can be monitored directly. There is a need to identify and assess aspects of human performance that relate to plant safety and to develop measures that can be used to develop technical bases for the development of human factors review guidance.

The objective of this paper is to describe an approach for establishing a technical basis from which human performance measures could be developed. First, an analysis of historical data is presented that provides evidence of a connection between human performance and overall plant performance. Second, a review of potential measures derived from industry models of human performance and processes in nuclear power plants is presented. Third, a modeling and simulation approach is proposed which demonstrates the relationship between human and plant performance.

\section{STUDIES CONNECTING HUMAN AND PLANT PERFORMANCE}

As one of the initial steps to establishing a technical basis for human performance measures, an empirical analysis of human performance and nuclear plant performance data available to the NRC was performed. The data for this analysis came from two sources. The human performance data was obtained from the
NRC's Human Factors Information System (HFIS). HFIS is a database that provides a general overview of the types and approximate numbers of human performance issues documented by either the NRC or licensees. Plant performance data were the PIs for the cornerstones of the ROP. The HFIS data used in the analysis were the number of human performance related "hits" or causal factors extracted from NRC Inspection Reports (IRs) and Licensee Event Reports (LERs). These data were available for the years 2000 through 2004. Three ROP Performance Indicators (PIs) were used in the analysis: unplanned scrams per 7,000 critical hours, unplanned power changes per 7,000 critical hours, and safety system unavailability. These are referred to as initiating events $\# 1$ and $\# 3$, and mitigating systems \#1 respectively, which corresponds to how they are listed in [3]. The initial results showed that human performance is statistically significantly related to a plant's safety performance. For example, the probability of safety system unavailability was 5 times higher for plants that had a "high" number of HFIS hits the previous year. More details about this analysis can be found in [4].

The general conclusion from this analysis of existing data is that there is, in fact, empirical support showing human performance is related to and affects overall plant performance. The analysis shows that as human performance degrades at nuclear power plants, the likelihood increases that plant performance is also degrading. These results are corroborated by past research [1], which studied the direct contributions of human performance to risk in significant operating events at commercial nuclear power plants. The NRC Accident Sequence Precursor (ASP) Program and the Human Performance Events Database (HPED) were used to identify safety significant events in which human performance contributed to changes in risk. The sensitivity analyses performed using these data showed that human performance was a major contributor to analyzed events. Two hundred and seventy human errors were identified in the events reviewed and multiple human errors were involved in every event. Latent failures (i.e., errors committed prior to the event whose effects are not discovered until an event occurs) were present four times more often than were active errors (i.e., those occurring at or following event initiation). The latent errors included failures to correct known problems and errors committed during design, maintenance, and operations activities. Based on both 
of these findings, there is evidence that indicates a connection between human performance and plant outcomes.

\section{INDUSTRY FRAMEWORKS AND HUMAN PERFORMANCE PROGRAMS}

Various nuclear industry groups and associations, such as the Institute of Nuclear Power Operations (INPO), the Electric Power Research Institute (EPRI), and the Nuclear Energy Institute (NEI) have written guidance documents on human performance and work processes in nuclear power plants. These reports have been written in part to support ongoing efforts to provide practical tools for performance improvement (e.g., measures of human performance). One document jointly written by NEI, EPRI, and INPO [2] could serve as a starting point for a framework to develop an approach to measuring human performance. For example, the "the human performance process map" in this document has the potential to be an excellent starting point because it provides an integrated framework of organizational factors and performance improvement, and because it explicitly shows how organizational factors can contribute to a variety of human errors in the workplace. Specifically, the human performance process map shows the actions and resource inputs needed to achieve the desired outputs. This process map can be used as a framework in a modeling and simulation approach because it has the basic input and output elements for nuclear power plants already mapped out. With an accepted and representative framework developed by the nuclear industry in place, the issue of model validity for this modeling and simulation approach to develop human performance measures is addressed.

In addition, a number of individual utilities, under their own initiative, have created a variety of in-house programs and efforts to track and trend human performance. These programs are based on guidance documents created by industry organizations based on research by Reason [5]. These programs could provide their data as one of the input sources for the modeling and simulation approach being proposed to develop human performance measures. In particular, a number of individuals from a variety of nuclear power plants in the US have shared their human performance measurement programs to the NRC, and in some instances given data from their program for use by the NRC and this research effort. As the modeling and simulation approach continues to develop, it is anticipated that these data could provide valuable input and possibly validate the approach.

\section{HUMAN PERFORMANCE MODELING AND SIMULATION}

It is acknowledged that the impact of human performance on nuclear power plant safety and operations is very important, but it is also difficult to ascertain. The difficulty arises from the complexity of nuclear plant operations and the many pathways by which human performance can affect operations. Regulators want to be assured that a plant is operating safely. This means that the physical system must be adequately designed, operated, and maintained. What the regulators might also use is some means of knowing that the managerial and organizational system is also adequately designed, operated and maintained. This latter issue is where modeling can be very useful.

The difficulty is that operators of a nuclear power plant cannot address human performance issues experimentally. For example, senior management cannot create a new reward system to encourage changed behavior in the operations or maintenance staff and quickly discover whether or not the change is working. It would take years to decide if a new policy is producing desired results. Indeed, even knowing what to measure to ascertain if the performance is improving is difficult. Complicating matters is the complexity of operations systems and the fact that changes may propagate in very diffuse ways.

This difficulty is what gives modeling and simulation approaches their great power and usefulness. If one can adequately represent the system in a model then system performance can be assessed by multiple simulations. The impacts of various proposed new policies, be they managerial or regulatory, can be analyzed, studied, and assessed. It is the rapid, quantitative, nondestructive testing of policy options that makes models so useful.

The key issue is to find a means of constructing a model that adequately represents the real system being modeled. While this issue is partially addressed with the use of the human performance process map described in [2], other possible issues and approaches are also considered. Another issue in this approach is to show how its representation of the real system, (i.e., the system's behaviors, how changes in the system produce different outcomes, etc.) can provide useful information to decision-makers (e.g., regulators). Modeling can help inform regulatory assessments by showing how interrelated plant outcomes such as safety, productivity, and quality can be associated with human performance. While human performance only partially explains plant outcomes, the association, even if non-linear, is consistent and predictable. In what follows, a possible modeling and simulation approach is outlined that makes explicit the relations between the plant organizational structure, the nature of the work done in different sectors of the organization, and the performance of the workforce that accomplishes the work. This approach is based on modeling and simulation work developed by HGK Associates [6], which is complimentary to the efforts to use industry developed and accepted frameworks and process maps [2]. The purpose of this section is to present in more detail an initial representation, or model, of the effort to incorporate human performance into overall performance at nuclear power plants. Two basic models (for plant management and maintenance department) are described below with a particular emphasis placed on how human performance issues can be incorporated.

Model development begins by identifying the set of activities within the plant and how these activities are conducted. It is convenient to distinguish activities according to the different components of the organization. A typical organization chart for a nuclear power plant is shown in Fig. 1. Only those sectors of the organization that are important to safety are included, and other sectors and functions such as personnel, payroll, and accounting are omitted. 


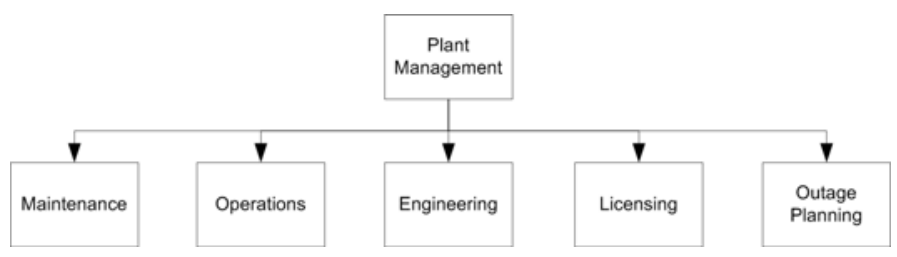

Figure 1. Typical Nuclear Power Plant Organizational Structure

The key to creating a model is to identify what types of work occurs in a sector, and what types of personnel carry out the work (i.e., the work process). Also, the policies that guide allocation of resources to various tasks must be identified. The maintenance sector is discussed in detail.

\section{Mainenance Sector}

The maintenance sector is complex in terms of the quantity and nature of the work to be done, and in the composition of the workforce. The workforce is usually composed of: sector management, management support staff, craft supervisors, craft labor, and craft support personnel. The different types of workers carry out different types of work. Craft labor work is illustrated. The work types for the crafts include: inspection work, corrective work, preventative maintenance, and quick fix work. The overall flow of work is shown in Fig. 2.

Note that the breakdown of operations contains flows of materials in the form of rates. These rates enter and leave in quantities that obey a conservation principle. That is,

$$
\begin{gathered}
\text { Content }(\mathrm{t}+\mathrm{dt})= \\
\text { Content }(\mathrm{t})+(\text { Flow rate in }- \text { Flow rate out }) * \mathrm{dt}
\end{gathered}
$$

In Fig. 2, the workforce is a conserved quantity. Flows into and out of the manpower levels are not shown explicitly. Moreover, there is a separate flow for each type of work done within a sector.

The work generation rate is different for each type of work. Usually there is a steady component and a time varying component that depends upon plant conditions. For example, preventative maintenance work is usually on a long-term schedule that changes with plant conditions and/or sector management decisions. On the other hand, inspections are usually mandated and cannot be slipped easily.

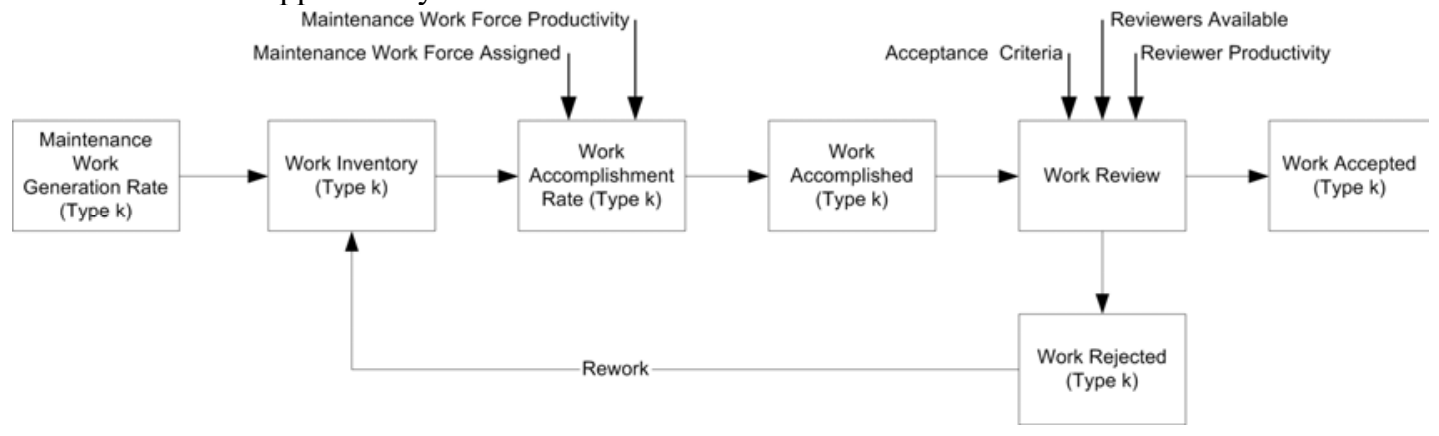

Figure 2. Maintenance Work Flow
The manpower level and craft productivity determines the work accomplishment rate. Maintenance staff productivity can be represented as a function of many factors such as: skill level, experience, training, supervisor availability, tools available, spare parts inventory, procedure quality, planning quality, and motivation. Note that motivation is a composite of several factors including the corporate reward system, the work environment, and growth prospects. Obtaining information on all of these factors is a key issue in model development. Working with plant managers it is possible to acquire data to help quantify such matters. In general, the productivity of craft personnel is represented as a multiplicative factor such as:

$$
\mathrm{P}(\mathrm{t})=\mathrm{P} 0 * \mathrm{fl}(\mathrm{t}) * \mathrm{f} 2(\mathrm{t}) * * * \mathrm{fn}(\mathrm{t})
$$

where $\mathrm{P} 0$ is the nominal productivity and the $\mathrm{fk}(\mathrm{k}=1,2, \ldots, \mathrm{n})$ are dimensionless multipliers on the base number. Thus, a workforce composed of all journeymen would have a maximum skill multiplier whereas a workforce composed of all apprentices would have a minimum skill multiplier.

All of the multipliers are time dependent and can change with many conditions. The overall staff skill level is a weighted composite of the skill of the total craft labor staff. As time goes on the experience level improves and apprentices migrate into the journeyman pool. One of the most rapidly varying factors is the supervisor availability. If conditions in the plant become abnormal, the supervisors may spend too much time in meetings and insufficient time with the workers reviewing work products, planning and scheduling work, and maintaining worker motivation.

Also note that not all of the work will be done correctly the first time. Thus, a quality factor is included that is a dimensionless quantity and represents the fraction of the work done correctly the first time. The quality of craftwork is represented in a similar fashion. That is,

$$
\mathrm{Q}(\mathrm{t})=\mathrm{Q} 0 * \mathrm{q} 1(\mathrm{t}) * \mathrm{q} 2(\mathrm{t}) * * * \mathrm{qn}(\mathrm{t})
$$

The modulating factors could be the same as for productivity, or different depending upon the beliefs of the plant operators.
All of the other sectors can be represented in a similar manner. That is, the sector work is broken down into its various parts and the creation and completion rates are analyzed. The work is done by a multi-component workforce whose individual 
performance characteristics are represented by productivities and work qualities.

It should also be noted that the sectors do not operate in isolation. The model must incorporate interactions in the form of collaborative work. Thus, the preparation and scheduling of a corrective work order will involve joint work between maintenance, operations, engineering, and possibly licensing. The degree to which coordination is done properly will impact both the productivity and quality of the repair. Staff is assigned to coordination work from all the involved sectors. Any sector that fails to assign adequate staff puts all the other sectors at risk of reduced performance.

\section{A. Developing Model Parameters}

Many of the variables in a model are easy to represent. For example, manpower levels can be obtained from historic records. Each sector has records that can be used to create a picture of the distribution of manpower throughout the system. Similarly, the flow of most types of work can be obtained from existing sector records. Given the time dependent values of work levels and schedules, it is usually easy to find the flow rates into and out of inventories. However, some generation rates will have to be obtained indirectly. For example, the amount of coordination work for a work order may have to be obtained by averaging over many examples.

Obtaining data on the factors that influence productivity and quality is much more complex than workflow data. Much of the data will have to be inferred from real experience. Thus, if plants have data on work output as a function of time, it may be possible to relate changes in productivity to other conditions in the plant. The most likely pathway to obtaining the factors is by interviews with plant staff and management via a Delphic process. Experience with models suggests that certain factors will emerge as the most significant factors in overall performance and one can concentrate extra effort on representing these factors.

\section{B. Safety Benefits from Modeling and Simulation}

The fundamental purpose for creating a model such as this is to help decision makers, whether they are regulators or the plant's management, understand how human performance can improve, or threaten, safe operation of a nuclear power plant. For example, a key concern regarding plant safety is the availability of safety systems. A decrease in availability could be a reflection of wear and tear in equipment, which is easily recognized. More subtle is a decrease in availability due to poor human performance in service and maintenance activities, or in surveillance and test activities. These deficiencies in turn may relate to a host of sources such as poor scheduling and coordination, inadequate work processes, inadequate work supervision, etc. A model of the type being proposed here would be useful in identifying and anticipating conditions that can lead to reduced safety.

For instance, the maintenance modeling and simulation example above can show how the quality and productivity of work affects safety and how their affect on safety depends on what the work is and what systems are involved. Suppose work ' $\mathrm{k}$ ' is to perform preventive maintenance on a pump. How productive the workers are and the quality their work will affect not only this pump, but pumps in safety equipment and in generation (and other) services. Modeling and simulation would allow, for example, the assessment of changes in staffing that might lead to changes in reviewer acceptance criteria for work because pumps are delayed in being returned to service. Safety would be impacted by the number of times the work is accepted when it should not be, which is driven by the context of the work situation. This is importantly different from human reliability analysis data that would simply say, on average, $\mathrm{x} \%$ of review acceptances are 'in error'.

Once a model has been created and validated it is possible to undertake numerous "what if" studies to better understand the impact of human performance on the system safety. Because of the explicit nature of the model one can trace the impact of policy changes. For example, retirement of senior supervisors can lead to reduced maintenance productivity, which can lead to an increasing work order backlog, which can lead to management concern and increased meetings, which can then propagate into other sectors of the plant. Thus, the model can be useful to decision makers by focusing on the human performance factors that impact work productivity and work quality in all sectors of the plant.

It is also important to remember that a plant model is organic. As new ideas emerge about what types of factors may impact performance it is easy to add these ideas into the model. Thus, there may be many factors that affect motivation of people. These ideas can be introduced into the model with out reworking the entire model. Likewise, it is easy to remove factors that are not significant.

\section{INTEGRATING HUMAN PERFORMANCE}

\section{MEASURES WITH CURRENT INDUSTRY PRACTICES}

The research questions this modeling and simulation approach address are what can be inferred from measurable plant outcomes such as productivity, quality, and safety to human performance at nuclear power plants? Additionally, can these outcomes be characterized by specific measures and then related to other measures that provide decision makers with advanced notification of declining human performance or degrading conditions? If so, how? More precisely let $\mathrm{M}=\mathrm{Set}$ of plant outcome measures. The challenge is then to develop a function $\mathrm{F}(\mathrm{X}): \mathrm{X} \subseteq \mathrm{M}$ through modeling and simulation that correlates human performance with measurable plant outcomes. In broad terms the desired mapping could be as described in (4).

The simulation of a model such as the ones described in this paper could establish the mapping of this function. The goal of such a function would be to provide an indication for additional actions such that potential problem areas are addressed prior to their manifestation into a reportable safety related event. When a boundary condition is exceeded (i.e., a Yellow or Red condition), further investigation and follow-up actions may be 


$$
\mathrm{F}(\mathrm{X})=\left\{\begin{array}{lll}
\text { Green } & \rightarrow & \text { Human performance within the expected range } \\
\text { White } & \rightarrow & \text { Human performance outside of expected range, but is still acceptable } \\
\text { Yellow } & \rightarrow & \text { Human performance is acceptable, but safety margin has been reduced } \\
\text { Red } & \rightarrow & \text { A significant reduction in the safety margin due to human performance }
\end{array}\right.
$$

warranted. Under normal conditions (i.e., Green and White), follow-up investigations may not be necessary.

\section{CONCLUSION}

It is recognized that the development and acceptance of performance measures is nontrivial. They must be defendable and obtainable within the bounds of industry. In addressing human performance assessment, Wreathall [7] has suggested that human performance measures should have the following characteristics:

- Objective: it should not be easily manipulable by plants or involve judgments that can be arbitrary.

- Quantitative: this allows it to be trended and compared with other measures.

- Available: if possible, additional measurements by plants should be avoided as an issue of efficiency.

- Simple to understand/represent worthy goals/possess face validity: since plants will tend to "manage the measure', having the measure represent a worthy goal will tend to improve performance in itself.

- Related to/compatible with other programs: if possible, measures should be integrated into existing programs to affect efficiency as minimally as possible.

These are examples of the standards to which individual or collective measures must be assessed, especially if such measures will be utilized as a basis for further diagnosis.

The advantages of the modeling and simulation approach are numerous. The framework for the approach was developed by the industry and the measures are to a large degree based on data already collected and even used in current business practices. Thus, the information should be obtainable without significant burden to the utilities, the measures developed should be valid and reliable, and the approach should meld with the current measures of plant performance and thus is not a significant change in philosophy. Additionally, this overall approach would provide industry with self-assessment measures and trending tools standardized across the industry that are specifically designed to assess human performance.

There is a need to identify and assess aspects of human performance that relate to plant safety and to develop measures that can be used to help develop the technical bases for the development of human factors review criteria. From the evidence presented in this paper, a technical basis for the development of measures of human performance exists through modeling and simulation approaches that use industry developed frameworks of organizational and human performance and existing human performance data from nuclear power plants.

\section{REFERENCES}

[1] NUREG/CR-6753, Review of Findings for Human Performance Contribution to Risk in Operation Events, 2002.

[2] NEI LP002, Human Performance Process Benchmarking Report, 2001

[3] NEI 99-02 (Rev. 3), Regulatory Assessment Performance Indicator Guideline, 2005.

[4] B. Hallbert, J. Joe, L. Blackwood, D. Dudenhoeffer, \& K. Hansen, "Developing Human Performance Measures". Proceedings of the 8th International Conference on Probabilistic Safety Assessment and Management, PSAM-0207, 2006.

[5] J. Reason, Organizational Accidents: The Management of Human and Organizational Factors in Hazardous Technologies, Cambridge University Press, Cambridge, England, 1997.

[6] K. Hansen, M. Golay, and S. Kwak, "OPSIM: The Nuclear Power Plant Management and Operations Simulator," HGK Associates, LLC, 2000.

[7] J. Wreathall, "Leading Indicators of Human Performance," Paper presented at the ASQ Energy and Environmental Division - Annual Conference, Tucson, AZ, 2000. 